\title{
First detection of Echinococcus multilocularis in Sweden, February to March 2011
}

E Osterman Lind ${ }^{1}$, M Juremalm ${ }^{1}$, D Christensson ${ }^{1}$, S Widgren $^{1}$, G Hallgren ${ }^{1}$, E 0 Ågren ${ }^{1}$, H Uhlhorn ${ }^{1}$, A Lindberg

(ann.lindberg@sva.se) ${ }^{1}, M_{\text {Cedersmyg }}{ }^{2}, \mathrm{H}$ Wahlström ${ }^{1}$

1. National Veterinary Institute (SVA), Uppsala, Sweden

2. Swedish Board of Agriculture, Jönköping, Sweden

Citation style for this article:

Osterman Lind E, Juremalm M, Christensson D, Widgren S, Hallgren G, Ågren EO, Uhlhorn H, Lindberg A, Cedersmyg M, Wahlström H. First detection of Echinococcus multilocularis in Sweden, February to March 2011. Euro Surveill. 2011;16(14):pii=19836. Available online: http://www.eurosurveillance.org/ViewArticle.

aspx?Articleld $=19836$

Article published on 7 April 2011

Surveillance for the fox tapeworm, Echinococcus multilocularis, has been carried out in Sweden since 2000 , with about 300 red foxes analysed annually. We report the first finding of $E$. multilocularis in Sweden, in a fox shot in December 2010 in the south-west of the country. A second infected fox shot in the same location was detected in March 2011. This paper describes the national monitoring programme and the ongoing work to estimate the prevalence and spread of the infection.

\section{Detection of Echinococcus multilocularis in red foxes in Sweden}

In February 2011, E. multilocularis was detected for the first time in the south-west of Sweden, in a red fox (Vulpes vulpes) shot in December 2010. A second infected fox, shot in the same location, was detected in March 2011.

\section{Background}

E. multilocularis is endemic in large parts of Europe and has been increasingly reported in animals from countries near Sweden, such as Latvia, Estonia and Denmark [1-4]. Although a rare disease in humans, it is of considerable public health concern due to its high mortality if untreated as well as high treatment costs [5]. In Sweden, infection with E. multilocularis in humans and all animal species are notifiable. Due to detection of the parasite in foxes in Denmark in 2000, a surveillance programme was initiated in Sweden in the same year. The surveillance is designed and implemented by the National Veterinary Institute and financed by the Board of Agriculture. It makes use of hunters submitting foxes for examination on a voluntarily basis, against a small remuneration. From 2000 to 2009, a total of 2,962 red foxes (Vulpes vulpes), 68 raccoon dogs (Nyctereutes procyonoides) and 35 wolves (Canis lupus) were examined for E. multilocularis: all were negative [6]. Samples from most foxes $(n=2,675)$ were examined by ELISA for the presence of the E. multilocularis coproantigen [7] and the rest, plus those from which samples were ELISA positive, were examined using the sedimentation and counting technique $(\mathrm{SCT})(\mathrm{n}=726)$ [8]. The raccoon dogs and wolves were examined by SCT. Since 2000, a total of 6,455 hunted foxes have been submitted for E. multilocularis analysis.

\section{Surveillance in 2010}

During 2010, 304 foxes were examined for E. multilocularis. A total of 103 were tested by SCT and 201 by taeniid egg isolation and real-time PCR. One fox, analysed in February 2011, was found to be positive - a young female, shot in December 2010 in Västra Götaland county, in south-west Sweden (Figure). A faecal sample from the fox was examined by egg flotation [9] followed by detection of egg DNA by real-time $P C R$, using an in-house protocol. The result was confirmed by conventional PCR [9] followed by sequencing. Furthermore, the intestine of the fox was examined by SCT and the parasites present were identified as E. multilocularis, both morphologically and by detection of parasite DNA by real-time PCR and sequencing. Although no formal counting of all worms was done, it was estimated that the animal harboured more than 500 tapeworms. Of the remaining 303 foxes found to be negative, 54 originated from the same county.

\section{Surveillance in 2011}

After the positive finding in February 2011, the sampling of foxes was intensified. In the south-western part of Sweden, hunters were requested to submit approximately 10 foxes per municipality in the 93 municipalities in the four counties (Skåne, Blekinge, Halland and Västra Götaland), and four foxes from each of the remaining 197 municipalities in other parts of Sweden. This intensified sampling ceased with the end of the hunting season (i.e. between 28 February and 31 March, ending at the earlier date in the south). By 31 March 2011, a total of 3,189 foxes had been submitted for screening. This sample size is sufficient to detect a prevalence of $0.1 \%$ on a country basis, with approximately $95 \%$ confidence. The intestines of the foxes were examined by the segmental sedimentation and counting technique (SSCT), which is more costeffective compared with SCT, but still has a very high 
sensitivity [10]. A total of 1,140 foxes had been analysed for $E$. multilocularis by 31 March 2011: one additional fox was found to be positive, an adult female, shot in early March in the same location and by the same hunter as the first infected fox (Figure).

In addition to surveillance of foxes, faecal samples are being collected from 140 hunting dogs in the four municipalities around the parish where the infected

\section{FIGURE}

Geographical distribution of all georeferenced ${ }^{a}$ foxes shot in Sweden and analysed for Echinococcus multilocularis, 1 January-31 March $2011(\mathrm{n}=1,025)$

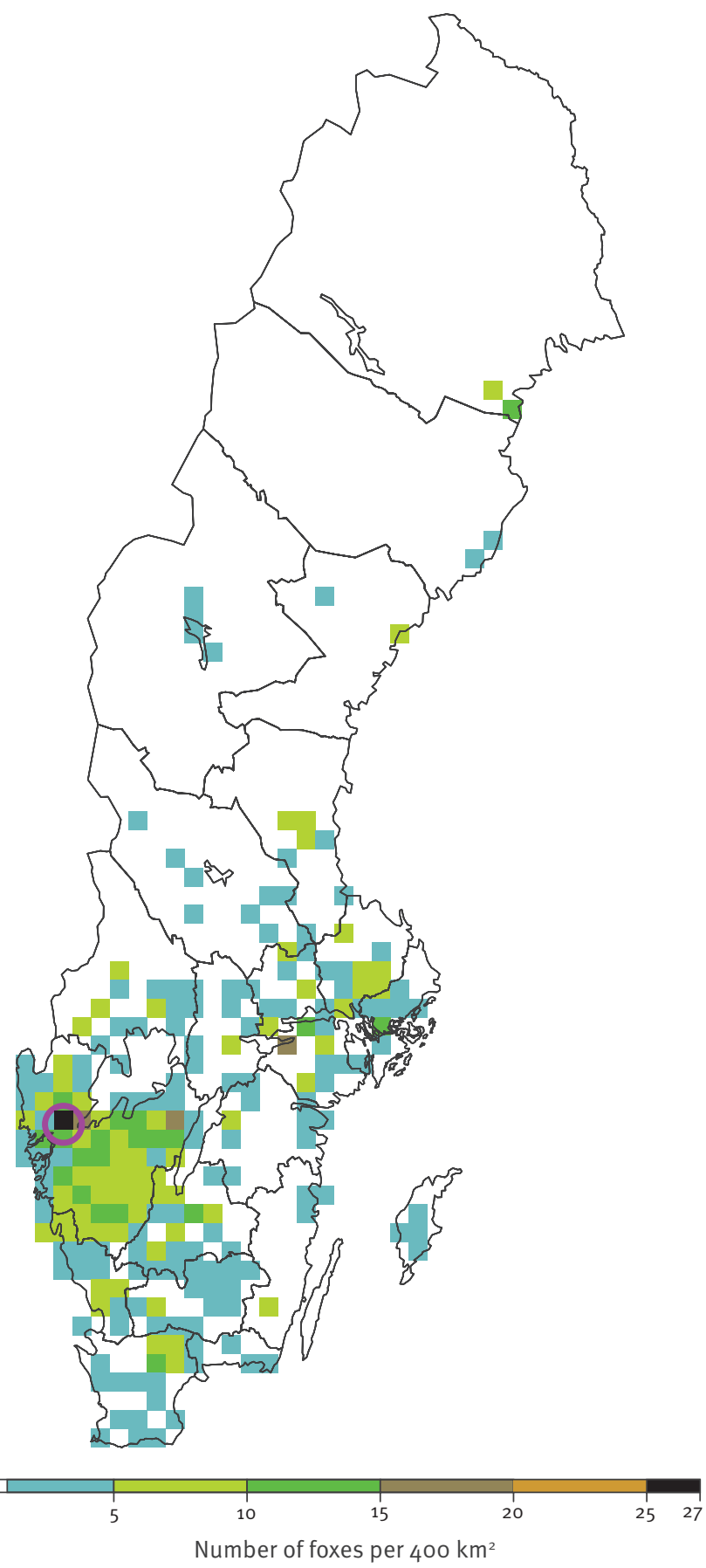

The circle indicates the location where the two E. multilocularispositive foxes were shot: one in December 2010 and one in March 2011. The lines indicate the county boundaries.

a Coordinate system RT9o. foxes were shot, and surveillance in rodents will be initiated once the snow cover has melted.

\section{Discussion}

It is not yet known how and exactly when E. multilocularis was introduced into Sweden. However, considering the frequency of dog movements between Sweden and countries in Europe where the parasite is present, it is regarded as most probable that it was introduced by a dog, despite the legal requirement to deworm dogs before entering the country. Assessments of the risk of introducing $E$. multilocularis into Sweden and the United Kingdom have highlighted dog movement as a risk factor $[11,12]$. An event that further supports this hypothesis is the introduction in 2003 of another dog-borne parasite (non-zoonotic), the French heartworm (Angiostrongylus vasorum) on the coast of Västra Götaland county, where E. multilocularis has now been found [13]. This is similar to the situation in Denmark, where $E$. multilocularis was first found in the area where $A$. vasorum had been introduced some decades earlier (unpublished data). This emphasises the need for efficient methods to prevent introduction of the parasite to other $E$. multilocularis-free countries.

After the identification of E. multilocularis in Sweden, deworming of dogs and cats has been recommended by the authorities in the four municipalities surrounding the location where the positive fox was shot. These recommendations also apply to dogs and cats entering and leaving this area. Guidance regarding safety precautions has been issued to hunters handling foxes, in line with recommendations given in other countries where E. multilocularis occurs [14].

At present, the geographical extent of E. multilocularis infection is not known. However, the fact that there were two positive foxes in the same location indicates that this may not be merely a place to which the foxes had wandered and that it may harbour intermediate hosts. The ongoing surveillance is expected to provide more information once up to 3,000 foxes have been examined by early summer this year, and once the dog and rodent screenings have been finalised. However, as the prevalence of $E$. multilocularis infection may be very low, extensive sampling may be needed to define the affected area.

Conditions for the establishment of $E$. multilocularis in Sweden are likely to be favourable: the climate is temperate, allowing worm eggs to survive in the environment for extended periods, and rodents reported to be intermediate hosts of the parasite - such as the water vole (Arvicola amphibius (terrestris) and the bank vole (Myodes glareolus) - are prevalent. Furthermore, in the northern parts of Sweden, other known intermediate hosts such as muskrats (Ondatra zibethicus) and lemmings (Lemmus lemmus) are present. The surveillance of rodents is aimed at clarifying which species in Sweden are intermediate hosts. Future actions will depend on the results of the surveillance efforts. 


\section{References}

1. Romig T, Dinkel A, Mackenstedt U. The present situation of echinococcosis in Europe. Parasitol. Int. 2006;55 Suppl:S187-91.

2. Bagrade G, Šnábel V, Romig T, Ozolinš J, Hüttner M,

Miterpáková M, et al. Echinococcus multilocularis is a frequent parasite of red foxes (Vulpes vulpes) in Latvia. Helminthologia. 2008;45(4):157-61.

3. Moks E, Saarma U, Valdmann H. Echinococcus multilocularis in Estonia. Emerg Infect Dis. 2005;11(12):1973-4.

4. Saeed I, Maddox-Hyttel C, Monrad J, Kapel CM. Helminths of red foxes (Vulpes vulpes) in Denmark. Vet Parasitol. 2006;139(1-3):168-79.

5. Torgerson PR, Schweiger A, Deplazes P, Pohar M, Reichen J, Ammann RW, et al. Alveolar echinococcosis: from a deadly disease to a well-controlled infection. Relative survival and economic analysis in Switzerland over the last 35 years. J Hepatol. 2008;49(1):72-77.

6. Wahlström H, Isomursu M, Hallgren G, Christensson D, Cedersmyg $M$, Wallensten $A$, et al. Combining information from surveys of several species to estimate the probability of freedom from Echinococcus multilocularis in Sweden, Finland and mainland Norway. Acta Vet Scand. 2011;53:9.

7. Deplazes P, Alther P, Tanner I, Thompson RC, Eckert J. Echinococcus multilocularis coproantigen detection by enzyme-linked immunosorbent assay in fox, dog, and cat populations. J Parasitol. 1999;85(1):115-21.

8. Eckert J, Deplazes P, Craig PS, Gemmell MA, Gottstein B, Heath $D$, et al. Echinococcosis in animals: clinical aspects, diagnosis and treatment. In: Eckert J, Gemmell MA, F.-X. Meslin,

Pawłowski ZS, editors. WHO/OIE Manual on echinococcosis in humans and animals: a public health problem of global concern. Paris: World Organisation for Animal Health; 2001. p. 73-94.

9. Mathis A, Deplazes P, Eckert J. An improved test system for PCR-based specific detection of Echinococcus multilocularis eggs. J Helminthol. 1996;70(3):219-22.

10. Umhang G, Woronoff-Rhen N, Combes B, Boue F. Segmental Sedimentation and Counting Technique (SSCT): An adaptable method for qualitative diagnosis of Echinococcus multilocularis in fox intestines. Exp Parasitol. 128(1):57-60.

11. Torgerson PR, Craig PS. Risk assessment of importation of dogs infected with Echinococcus multilocularis into the UK. Vet Rec. 2009;165(13):366-8.

12. Vågsholm I. An assessment of the risk that EM is introduced with dogs entering Sweden from other EU countries without and with antihelmintic treatments. Uppsala: National Veterinary Institute; 2008. Available from: http://www.sva.se/ upload/pdf/ask/qra emdogsaugo6.pdf

13. Åblad B, Christensson D, Osterman Lind E, Ågren E, Mörner T. Angiostrongylus vasorum etablerad i Sverige [Angiostrongylus vasorum established in Sweden]. Svensk Veterinärtidning. 2003;55(12):11-5. Swedish.

14. Robert Koch Institute (RKI). Echinokokkose [Echinococcosis]. Berlin: RKI; 19 Nov 2010. German. Available from: http:// www.rki.de/cln_178/nn_196658/DE/Content/InfAZ/E/ Echinokokkose/Echinokokkose.html?_nnn=true 